\title{
Effects of SEBS-g-MA on rheology, morphology and mechanical properties of PET/HDPE
}

\author{
blends \\ Károly Dobrovszky, Ferenc Ronkay* \\ Department of Polymer Engineering, Faculty of Mechanical Engineering, Budapest University of \\ Technology and Economics, \\ H-1111 Budapest, Műegyetem rkp. 3, Hungary \\ * Corresponding author. Tel.: +36 1 463-2462. \\ E-mail address: ronkay@pt.bme.hu (F. Ronkay).
}

\begin{abstract}
:
The effects of additive styrene/ethylene-butylene/styrene copolymer grafted with maleic anhydride (SEBS-g-MA) were investigated on the rheology, morphology and mechanical properties of a polyethylene terephthalate (PET) / high density polyethylene (HDPE) blend. The ratio of the two components was changed in small increments to track phase inversion. The rheology measurements show that SEBS-g-MA acts differently on HDPE and PET, as different morphologies are formed due to viscosity ratio change. With the help of electron microscopy various phases after extrusion and after injection moulding were revealed and identified. Because of the high viscosity of HDPE the cocontinuous morphology was immediately formed when PET reached 30 vol\%. The range of the cocontinuous structure of the blend was wider when SEBS-g-MA was added, and the elongation at break also improved as additive content increased, without a significant strength decrease. The divergence of the mechanical properties from the theoretical value, i.e. the value determined by the mixing rule, can be explained by the changing phase structure.
\end{abstract}


Keywords: morphologic evolution; phase inversion; mechanical properties; mixing rule; polymer blend.

\section{Introduction}

The amount of polymers used has been continuously increasing in the past decade, by about $4 \%$ annually. As a consequence, municipal solid waste has been on the rise (Plastic Europe, 2013). Two or more polymer components are blended in order to tailor the good physical and mechanical properties of materials (Utracki, 2002), and blending also has recycling aspects. Polymer blends are widely used in several fields: for example in automotive, electronic and construction industry (Perugini et al., 2005; Scheirs, 1998). If two immiscible polymers are mixed, that can result in two different types of morphological structures: a dispersed phase/matrix type or a co-continuous phase. However, it is a well-known fact that most polymers are not compatible with each other, thus a suitable copolymer or a compatibilizer is needed to achieve good miscibility between the phases (Jarukumjorn and Chareunkvun, 2006; Li et al., 2014). Introducing a third part into polymer blends could also reduce the size of the dispersed phase and provide a significant improvement in adhesion between the phases (Marosi, 2011; Zhang et al., 2004).

In our study polyethylene terephthalate (PET) and high density polyethylene (HDPE) were investigated. They are immiscible with each other, and after cooling their blends show a heterogeneous morphology. In previous studies the morphology and mechanical properties of PET/HDPE blends were examined and the possibility of compatibilization was also mentioned. Torres et al. (2001) showed that PET and HDPE phases form a coarse dispersed morphology in case of blend 30/70 PET/HDPE without additive, while a finer dispersion was observed using ethyleneglycidyl methacrylate copolymer (EGMA), or high density polyethylene grafted with glycidyl methacrylate (HDPE-g-GMA). Jánoki and Ronkay (2010) investigated PET/HDPE blends in a wide 
range of composition ratios and found that the impact strength was the highest when the blend contained $60 \%$ PET.

The selected two plastics can be found in large amounts in post-consumer plastic waste, therefore research may also promote polymer waste recycling, as the compatibilizer reduces the brittleness of the mixed plastic waste (Aglietto et al., 2004; Pawlak et al., 2002; Yu et al., 2004; Zenkiewich and Kurcok, 2008). Pluta et al. (2001) compared two different compositions of recycled PET/HDPE blends using different types of compatibilizers. They claimed that styrene/ethylene-butylene/styrene copolymer grafted with maleic anhydride (SEBS-g-MA) and EGMA can improve the homogeneity of the phases. This effect has been mentioned in other research (Kalfoglou et al., 1995; Pracella et al., 2002) as well. Pluta et al. (2001) found that SEBS-g-MA improved elongation at break, although the best mechanical properties were achieved when EGMA compatibilizer was used.

The aim of the present paper is to investigate the effects of SEBS-g-MA on the rheology, morphology and mechanical properties of PET/HDPE blends.

\section{Experimental}

\subsection{Materials}

PET and HDPE have been chosen as the materials of the samples, in which the PET content ranges from 0 vol\% to 100 vol\%, by increments of 10 vol\%. PET was NeoPET 80 (density $1.34 \mathrm{~g} / \mathrm{cm}^{3}$, $T_{m}=248^{\circ} \mathrm{C}$ ) produced by Neogroup and HDPE was TIPLEN BA 550-13 (density $0.955 \mathrm{~g} / \mathrm{cm}^{3}$, MFI $0.35 \mathrm{~g} / 10 \mathrm{~min} ; 190^{\circ} \mathrm{C} / 2.16 \mathrm{~kg}$ ) produced by TVK (Hungary). Kraton FG1901X SEBS-g-MA compatibilizer (density $0.91 \mathrm{~g} / \mathrm{cm}^{3}$; MFI=22 $\mathrm{g} / 10 \mathrm{~min}, 230^{\circ} \mathrm{C} / 5 \mathrm{~kg}$ ) was added to the PET/HDPE blend in $4 \mathrm{vol} \%(=3.64 \mathrm{wt} \%)$.

\subsection{Equipment}

PET was dried for 6 hours in an air drying oven at $160^{\circ} \mathrm{C}$. The complex viscosities were recorded using an AR2000 rheometer (TA Instruments) in plate-plate configuration. The $25 \mathrm{~mm}$ diameter discs 
were compression moulded from the blends for 5 minutes at $275^{\circ} \mathrm{C}$. Extrusion was carried out in a Labtech Scientific LTE 26-44 twin screw extruder (temperature 250 to $275^{\circ} \mathrm{C}$, rotation speed $40 \mathrm{rpm}$ ). The samples were injection moulded in an Arburg Allrounder Advance 370S 700-290, and the following parameters were set: melt temperature $280 \pm 5^{\circ} \mathrm{C}$, injection flow $40 \pm 10 \mathrm{~cm}^{3} / \mathrm{s}$, injection volume $46 \mathrm{~cm}^{3}$, holding pressure $850 \pm 150 \mathrm{bar}$ - depending on the mixture, cycle time $60 \mathrm{~s}$. Tensile tests were performed on a Zwick Z020 Tester (test speed $20 \mathrm{~mm} / \mathrm{min}$, clamping distance $100 \mathrm{~mm}$ ) at room temperature. JEOL JSM 6380LA scanning electron microscope (SEM) was used at an acceleration voltage of $15 \mathrm{kV}$ to study the morphological structures of the blends.

\section{Results and discussion}

\subsection{Rheology}

The complex viscosities of plastics (PET and HDPE), with and without SEBS-g-MA are shown as a function of shear rates $(\dot{\gamma})$ in Fig 1 . SEBS-g-MA acts differently on the components. In both cases the complex viscosity of PET that contained SEBS-g-MA was higher than that of pure PET in a way that the difference was the same at every shear rate and the two curves follow a similar trend. On the other hand, the viscosity of HDPE that contained SEBS-g-MA changed differently than that of HDPE without additive, as a function of shear rate (Fig. 1/a). The curves of pure HDPE and HDPE that contains SEBS-g-MA differ in the slope of the curve, as the curve of the HDPE without SEBS-g-MA decreases to a greater extent at high shear rates. Thus, the viscosity ratio of the componentsalso changes differently, as a function of shear rate (Fig. 1/b) depending on the presence of SEBS-g-MA.

Fig. 2 represents the complex viscosities of PET/HDPE blends with and without 4 vol\% SEBS-g-MA additive as a function of shear rates $(0.1,1.0$ and $10.01 / \mathrm{s})$ at a temperature of $275^{\circ} \mathrm{C}$. The complex viscosities of both blends decreased as the PET content of blends increased. Blends with SEBS-gMA have smaller viscosity at small PET vol\% than blends without additive. Nevertheless, over 80 vol\% PET this trend reverses, and blends that contain SEBS-g-MA have higher viscosity, presumably due to the fact that the additive significantly increases the viscosity of PET. In previous studies 
chemical interaction between maleic anhydride groups of SEBS-g-MA and hydroxyl end-groups of PET was also explained (Ihm and White, 1996; Lei et al., 2009; Tanrattanakul et al., 1997). These results confirm the assumption of the present paper.

\subsection{Morphology}

\section{Morphology after extrusion}

The morphology of different PET/HDPE blends, with and without 4 vol\% SEBS-g-MA compatibilizer was investigated in two different directions after extrusion: parallel to the shear flow and perpendicular to it, with the help of electron microscopy. The 10/90 PET/HDPE blend showed a dispersed morphology, where the spherical and thin, rod-like PET particles spread in the matrix layer of HDPE (Fig. 3). If the the blends are compared, it can be stated that the 10/90 PET/HDPE blend with 4 vol\% SEBS-g-MA has a much finer dispersed morphology with spherical PET phases, while in case of the 10/90 PET/HDPE blend the PET phases form a thin, elongated, rod-like dispersed morphology in the HDPE matrix. In the 20/80 PET/HDPE blends a similar dispersed morphology structure evolved, however, in blends that contain SEBS-g-MA PET formed a fibre-like structure.

The 30/70 PET/HDPE blends without compatibilizer have fully co-continuous morphology on both sides (Fig. 4/a), in contrast to blends with SEBS-g-MA with both continous and dispersed phases (Fig. 4/c) due to the early stage of phase inversion. If the proportion of PET in the blend is increased to 40 vol\% the co-continuous morphology transforms into dispersed structure in blends without SEBS-g-MA (Fig. 4/b), while in blends that contain SEBS-g-MA the co-continous phases are equally dominant (Fig. 4/d). This means that phase inversion was highly asymmetric at30 vol\% PET in case of PET/HDPE blends without SEBS-g-MA, however, additive SEBS-g-MA widens the range of cocontinuous structure in PET/HDPE blends, perhaps due to the fact that SEBS-g-MA chemically interacts with the hydroxyl end-group of PET. On the basis of this fact, the emerged new connections between the molecular chains could change the visocisty of PET, and that explains the widening range of phase inversion in PET/HDPE blends that contain SEBS-g-MA. 
In the 50/50 PET/HDPE blends without compatibilizer, the high fluid of PET is surrounded by thin, elongated, rod-shaped HDPE dispersed phases, meanwhile the dispersed structure of the phases only begins to develop in the 50/50 blends with 4 vol\% SEBS-g-MA. Thus parallel with the flow direction the two phases are next to each other forming a fibrous structure. Fig. 5 represents the morphology of 60/40 PET/HDPE blends. In blends without SEBS-g-MA the large diameter HDPE droplets are also present in the minor HDPE phases along with the rod-shaped formation, while blends with 4 vol\% SEBS-g-MA remain fully fibrous in the minor HDPE phase, similarly to the 50/50 composition.

A similar trend can be observed in case of blends with higher proportion of PET. At 80 vol\% PET content, in the blends without additive, the HDPE phase is almost purely droplet-like. However, the elongated, thin, rod-shaped HDPE phase still remains over 90 vol\% PET content in blends containing SEBS-g-MA (Fig. 6).

If 90/10 and 10/90 PET/HDPE blends are compared, it can be stated that the average diameter of droplets in blends without SEBS-g-MA is almost the same $(1.17 \pm 0.30 \mu \mathrm{m}$ and $0.90 \pm 0.26 \mu \mathrm{m}$, respectively). When 4 vol\% SEBS-g-MA was added the minor PET phases showed a much finer distribution in the HDPE matrix in 10/90 PET/HDPE blends (Fig. 3/b). On the other hand, HDPE minor phase did not spread in 90/10 PET/HDPE blends with SEBS-g-MA, and the average thickness of HDPE phases was 4 times higher than the diameter of HDPE rods in 90/10 blends without SEBSg-MA. This suggests that SEBS-g-MA promotes finer dispersion of PET phases in HDPE matrix, and inhibits the spread of finer HDPE droplets in the PET matrix meanwhile.

\section{Morphology after injection moulding}

In case of injection moulding, as the composition ratio was altered, morphology changed similarly to what we have experienced in case of extrusion. Thus, blends had dispersed morphology up to 20 vol\% PET in the core (Fig. 7). The effects of SEBS-g-MA can also be detected, since blends with the additive showed smaller average diameter inside the core, and the fibrous structure was finer inside the shell zone. In case of 30-40 vol\% PET a co-continuous morphology developed in both the shell 
and the core (Fig. 8), but the different orientations can also be observed in the pictures. It can be stated that injection moulded samples had a wider range of phase inversion (30-40 vol\% PET), particularly when they did not contain SEBS-g-MA, since phase inversion occurred exactly at 30 vol\% PET in extruded blends. Due to the different processing methods the co-continuous state was wider in PET/HDPE blends without SEBS-g-MA. After phase inversion fibrous shell / dispersed core morphology can be observed up to 60 vol\% PET (Fig. 9). Over 60 vol\% PET the fibrous structure started to break up into elongated droplets in the shell zone, and only elongated droplets are present at 80 vol $\%$ PET.

Morphology is significantly different in 90/10 PET/HDPE blends (Fig. 10). In case of blends without SEBS-g-MA dispersed HDPE phases are much finer (Fig. 10/a) than in blends that contain SEBS-gMA - while the component ratio is the same -, wherein HDPE keeps a large, coarsened dispersed structure in the core (Fig. 10/b). This phenomenon corresponds to the results of morphology after extrusion, and can be explained by the change of the viscosity ratios of PET and HDPE (Fig. 1). It is well known that the average diameter of dispersed phases strongly depend on the viscosity ratio of the components (Bayareh and Mortazavi, 2011; Canto, 2014; Fililppone et al., 2007; Guido, 2011; Lemenand et al., 2013), hence SEBS-g-MA coarse the dispersed phases in cases of certain compositions, escpecially from 80 to 90 vol\% PET in PET/HDPE blends.

During the evaluation of morphology, the specific characteristics of injection moulding should be taken into account as well, i.e. melted material is cooled rapidly under high shear stress, and forms a thin, frozen layer close to the wall. As a result of the expiratory flow, the residual melted polymer flows into the frozen sheath, and creates the core structure of the material. Since shear stress changes continuously in the direction of the wall due to the pseudo plastic behaviour of the blend, an elongated, fibrous structure is formed in the transition layer between the core and the shell. The thickness of the shell was between 300 and $500 \mu \mathrm{m}$, and the transition zone and the core were thicker. 
In previous studies (Jánoki and Ronkay, 2010; Lei and Wu, 2012; Mallette et al., 2001; Ravazi et al., 2011) phase inversion was reported to occur in the range of 40-60 vol\% PET content, and that is slightly different from the results of the present study, where phase inversion occurred at 30 vol\% PET in blends without SEBS-g-MA, produced by extrusion. After injection moulding the cocontinuous phase was formed at 30-40 vol\% PET content, in the present research. Based on the results it can also be stated that the different production methods also have an effect on morphology. This phenomenon can be explained by the characteristics of viscosity, since HDPE used can be characterized by low flowability and thermal stability at $275^{\circ} \mathrm{C}$, while PET had smaller viscosity at the same temperature (Fig 1.). Therefore, during processing it is difficult for high viscosity HDPE to create a continuous matrix structure, it prefers to form a dispersed structure in another material instead. On the contrary, in case of PET, which can be found in relatively small amounts, continuous structure is immediately formed once the required proportion is reached. The narrow range of the phase inversion in the blends can be explained by a similar reasons (30/70 to 40/60 vol\% of PET/HDPE). Since there was a large difference in the viscosities of the two materials, the developed morphology was rather determined by this property than by the composition ratio of the blend.

\subsection{Mechanical properties}

Tensile strength, Young's modulus and elongation at break of the samples were measured. The highest tensile strength (55.48 MPa) (Fig. 11) occurred at samples containing only PET while the lowest tensile strength (24.69 MPa) was measured in blends containing 100 vol\% HDPE with 4 vol\% SEBS-g-MA. Blends containing SEBS-g-MA had smaller tensile strength at every ratio of the two components, except 80/20 PET/HDPE, where the difference was also very small (38.84 MPa, 37.61 MPa, respectively). A huge, $30 \%$ increase was observed in the tensile strength in blends without SEBS-g-MA, between 80 and90 vol\% PET due to morphological reasons. The HDPE minor phase showed an elongated structure in blends with less than 80 vol\% PET after injection moulding, while above that HDPE transformed into a very fine, spherical form, inside both the core and the shell. 
Thus, 90/10 PET/HDPE blends (Fig. 10/a) had more homogeneous structure than 80/20 blends, and as a result of the finer morphology, tensile strength increased as well.

Fig. 11 illustrates how the tensile strength of blends differs from the value defined by the mixing rule, as shown in Eq. (1):

$$
\sigma_{M}=\sigma_{P E T} \cdot \varphi_{P E T}+\sigma_{H D P E} \cdot\left(1-\varphi_{P E T}\right)
$$

where $\sigma_{M}$ is the tensile strength of the blends at maximum force, $\sigma_{P E T}$ is the tensile strength of pure PET samples, $\sigma_{H D P E}$ is the tensile strength of pure HDPE samples and $\varphi_{P E T}$ is the ratio of PET in the PET/HDPE blends. In each sample lower tensile strength was measured than the value determined by the mixing rule regardless of SEBS-g-MA content, but it can be stated that the difference is larger in case of blends without SEBS-g-MA. Blends that contain SEBS-g-MA follow the determined, theoretical line of the mixing rule better, whereas the fibrous structure of HDPE remained even at high PET content.

If the ratio of PET is increased in PET/HDPE blends, a steady growth of Young's modulus can be observed (Fig. 12). The Young's modulus of blends was smaller in every component than the theoretical value determined by the mixing rule (Eq. (2)):

$$
E_{0}=E_{P E T} \cdot \varphi_{P E T}+E_{H D P E} \cdot\left(1-\varphi_{P E T}\right)
$$

where $E_{0}$ is the Young's modulus of the blend, $E_{P E T}$ is the Young's modulus of the pure PET samples, $E_{H D P E}$ is the Young's modulus of the pure HDPE samples and $\varphi_{P E T}$ is the ratio of PET in PET/HDPE blends. It can be concluded that Young's modulus of PET/HDPE without SEBS-g-MA differs (max. $10 \%$ ) only slightly from the theoretically established straight line. The difference in case of blends that contain SEBS-g-MA is larger in the negative direction from the mixing rule than in case of blends without additive due to the softening effect of SEBS-g-MA in PET/HDPE blends (Carté and Moet, 1993; Kalfoglou et al., 1995; Pracella et al., 2002). Because of the presence of SEBS-g-MA a finer fibrous structure was formed in the PET/HDPE blends. In these blends PET and HDPE are immiscible 
with each other, therefore the interfacial adhesion between the particles is quite poor, and that causes further differences in the Young modulus compared the line determined by the mixing rule.

In blends without SEBS-g-MA, in case of 0, 10 and 100 vol\% PET content, samples did not break up to $120 \%$ elongation. Samples that contained SEBS-g-MA - besides the composition mentioned above - did not break at 10 to 20 vol\% PET content due to the greater toughness of the material. As it can be observed from the aforementioned data, 4 vol\% of SEBS-g-MA improves the tensile elongation of PET/HDPE, compared to blends without this additive (Fig. 13). Between 30 and 80 vol\% PET blends without SEBS-g-MA were broken after a small deformation, while the elongation at break of blends that contained SEBS-g-MA was higher in every case. This phenomenon can be explained by the fact that the high tensile elongation of the additive improves the elongation at break of the blend; On the other hand, SEBS-g-MA widens the co-continuous range up to 40 vol\% PET content. In these cases HDPE also has continuous morphology, just like PET. On the contrary in blends without SEBSg-MA HDPE shows a dispersed phase structure in the PET matrix already at 40 vol\% PET content. The elongation at break becomes commensurable in blends that contain 60 to 70 vol\% PET, where HDPE shows highly elongated, dispersed morphology in both blends, regardless of SEBS-g-MA content. It is assumed that blends can only have high tensile elongation when the HDPE phase exhibits a continuous structure in PET/HDPE blends, or its presence does not weaken the associated PET matrix.

\section{Conclusion}

In this research the rheology, change of morphology and the mechanical properties of PET/HDPE blends with and without SEBS-g-MA additive were investigated. The results of rheological investigations show that SEBS-g-MA acts differently on the components: viscosity of PET was higher in a way that the difference was the same at every shear rate if it contained SEBS-g-MA; but the viscosity of HDPE that contain SEBS-g-MA changed differently than that of HDPE without the additive in the range where our measurements were carried out. The viscosity ratio of PET/HDPE 
blends changed differently depending on the presence of SEBS-g-MA, and that had an effect on the morphology of the blend.

In PET/HDPE blends produced by extrusion a fibrous structure was formed in the direction of the shear flow, in contrast to injection moulded samples where shell / core morphology could be observed. In case of extrusion phase inversion occurred at 30 vol\% PET, while injection moulded samples showed a wider range of co-continuous structure (30 to 40 vol\% PET) in PET/HDPE blends. The morphological studies show that co-continuous structure was also formed in an asymmetric composition because of the high viscosity of $\mathrm{HDPE}$ at $275^{\circ} \mathrm{C}$, and that proves that not only the content ratio, but also the viscosity ratio of the components has a significant effect on the morphology developed. Therefore, co-continuous morphology was immediately formed when PET reached the required proportion, i.e. $30 \mathrm{vol} \%$. When SEBS-g-MA was added to the PET/HDPE blends, the additive widened the range of phase inversion of the blends, especially in case of extrusion.

The results of mechanical tests revealed that SEBS-g-MA slightly decreases the tensile strength and the Young's modulus of PET/HDPE blends; while elongation at break improved in cases when the breakage took place under $100 \%$ elongation because of the toughening effect of SEBS-g-MA on the PET/HDPE blends.

According to the results of mechanical tests, the tensile strength of PET/HDPE blends without SEBSg-MA differs more from the theoretical value determined by the mixing rule. In contrast, the divergence of the Young's modulus was higher in cases of blends that contain SEBS-g-MA. Nevertheless, the largest differences were observed at symmetrical composition of PET/HDPE blends because of the fibrous structure, whether the blends contained SEBS-g-MA or not.

\section{Acknowledgements}


This research was realized in the framework of TÁMOP 4.2.4. A/1-11-1-2012-0001 "National Excellence Program - Elaborating and operating an inland student and researcher personal support system". The project was subsidized by the European Union and co-financed by the European Social Fund. The infrastructure of the research project was supported by the Hungarian Scientific Research Fund (OTKA K109224).

\section{References}

Aglietto, M., Coltelli, M-B., Savi, S., Lochiatto, F., Ciardelli, F., Giani, M., "Postconsumer polyethylene terephthalate (PET)/polyolefin blends through reactive processing", J. Mater. Cycles Waste Manage. 6, 13-19 (2004) DOI: 10.1007/s10163-003-0100-z

Bayareh, M., Mortazavi, S., "Binary collision of drops in simple shear flow at finite Reynolds numbers: Geometry and viscosity ratio effects", Adv. Eng. Softw. 42, 604-611 (2011) DOI: 10.1016/j.advengsoft.2011.04.010

Canto, L. B., "On the coarsening of the phase morphology of PP/EVA blends during compounding in a twin screw extruder", Polym. Test. 34, 175-182 (2014) DOI: 10.1016/j.polymertesting.2014.01.012

Carté, T. L., Moet, A., "Morphological origin of super toughness in poly(ethylene terephthalate)/polyethylene blends", J. Appl. Polym. Sci. 48, 611-624 (1993) DOI: 10.1002/app.1993.070480405

Filippone, G., Netti, P. A., Acerno, D., "Microstructural evolutions of LDPE/PA6 blends by rheological and rheo-optical analyses: Influence of flow and compatibilizeron break-up and coalescence processes", Polymer 48, 564-573 (2007). DOI: 10.1016/j.polymer.2006.11.050 
Guido, S., "Shear-induced droplet deformation: Effects of confined geometry and viscoelasticity", Curr. Opin. Colloid Interface Sci. 16, 61-70 (2011). DOI: 10.1016/j.cocis.2010.12.001

Ihm, D. J., White J. L., "Interfacial tension of polyethylene/polyethylene terephthalate with various compatibilizing agents", J. Appl. Polym. Sci. 60, 1-7 (1996). DOI: 10.1002/(SICI)10974628(19960404)60:1<1::AID-APP1>3.0.CO;2-T

Jarukumjorn, K., Chareunkvun, S., "Compatibilization of recycled high density polyethylene (HDPE)/polyethylene terephtalate (PET) blends", Suranaree J. Sci. Technol. 14, 1-8 (2006).

Jánoki, G., Ronkay, F., "Morphology and mechanical properties of immiscible polymer blends", Journal of Material Testers Magazine 20, 16-21 (2010).

Kalfoglou, N. K., Skafidas, D. S., Kallitsis, J. K., “Comparsion of compatibilizer effectiveness for PET/HDPE blends", Polymer 36, 4453-4462 (1995). DOI: 10.1016/0032-3861(95)96853-Z

Lei, Y., Wu, Q., Zhang, Q., “Morphology and properties of microfibrillar composites based on recycled poly (ethylene terephthalate) and high density polyethylene”, Composites: Part A 40, 904912 (2009). DOI: 10.1016/j.compositesa.2009.04.017

Lei, Y., Wu, Q., "High density polyethylene and poly(ethylene terephthalate) in situ sub-micro-fibril blends as a matrix for wood plastic composites", Composites: Part A 43, 73-38 (2012). DOI: 10.1016/j.compositesa.2011.09.012

Lemenand, T., Dupont, P., Della Valle, D., Peerhossaini, H., "Comparative efficiency of shear, elongation and turbulent droplet breakup mechanisms: Review and application", Chem. Eng. Res. Des. 91, 2587-2600 (2013). DOI: 10.1016/j.cherd.2013.03.017

Li, Z., Liu, C. M., Liu, H. L., Wang, K., Fu, Q., "Non-uniform dispersion of toughening agents and its influence on the mechanical properties of polypropylene", Express Polym. Lett. 8, 232-242 (2014). DOI: $10.3144 /$ expresspolymlett.2014.27 
Mallette, J. G., Quej, L. M., Marquez, A., Manero, O., “Carbon black-filled PET/HDPE blends: Effect of the CB structure on rheological and electric properties”, J. Appl. Polym. Sci. 81, 562-569 (2001). DOI: 10.1002/app.1471

Marosi, G. J. "Interfaces in Multiphase Polymer Systems", in Handbook of Multiphase Polymer Systems, Boudenne, L., Ibos, L., Candau, Y., Thomas, S. (Eds.), John Wiley \& Sons Ltd, Chichester, p. $81-112(2011)$

Pawlak, A., Morawiec, J., Galeski, A., "Compatibilization, processing and properties of postconsumer PET/polyolefin blends", Polimery 47, 491-499 (2002)

Perugini, F., Mastellone, M. L., Arena, U., “A Life Cycle Assessment of mehanical and feedstock recycling options for management of plastics packaging wastes”, Environ. Prog. 24, 137-154 (2005). DOI: $10.1002 /$ ep. 10078

Plastic Europe: Plastics - the Facts 2013, Belgium, 2013.

Pluta, M., Bartczak, Z., Pawlak, A., Galeski, A., Pracella, M., "Phase structure and viscoelastic properties of compatibilized blends of PET and HDPE recyclates”, J. Appl. Polym. Sci. 82, 14231436 (2001). DOI: 10.1002/app.1980

Pracella, M., Pazzagli, F., Galeski, A., "Reactive compatibilization and properties of recycled poly(ethylene terephtalate)/polyethylene blends", Polym. Bull. 48, 67-74 (2002). DOI: $10.1007 / \mathrm{s} 00289-002-0001-7$

Ravazi, S., Shojaei, A., Bagheri, R., "Binary and ternary blends of high-density polyethylene with poly(ethylene terephthalate) and polystyrene based on recycled materials", Polym. Adv. Technol. 22, 690-702 (2011). DOI: 10.1002/pat. 1567

Scheirs, J.: Polymer recycling science, technology, and applications. Wiley, New York (1998) 
Tanrattanakul, V., Hiltner, A., Baer, E., Perkins, W. G., Massey, F. L., Moet, A., "Toughening PET by blending with a functionalized SEBS block copolymer", Polymer 38, 2191-2200 (1997). DOI: 10.1016/S0032-3861(96)00774-4

Torres, N., Robin, J. J., Boutevin, B., "Study of compatibilization of HDPE-PET blends by adding grafted or statistical copolymers”, J. Appl. Polym. Sci. 81, 2377-2386 (2001). DOI: 10.1002/app.1678

Utracki, L. A.: Polymer Blends Handbook. Kluwer Academic Publishers, Dordrecht, 2002.

Yu, Z-Z., Yang, M-S., Dai, S-C., Mai Y-W., "Toughening of recycled poly(ethylene terephthalate) with a maleic anhydride grafted SEBS triblock copolymer", J. Appl. Polym. Sci. 93, 1462-1472 (2004). DOI: 10.1002/app.20592

Zenkiewich, M., Kurcok, M., "Effects of compatibilizers and electron radiation on thermomechanical properties of composites consisting of five recycled polymers", Polym. Test. 27, 420-427 (2008). DOI: 10.1016/j.polymertesting.2008.01.002

Zhang, Q., Yang, H., Fu, Q., "Kinetics-controlled compatibilization of immiscible polypropylene/polystyrene blends using nano-SiO 2 particles”. Polymer 45, 1913-1922 (2004). DOI: 10.1016/j.polymer.2004.01.037 

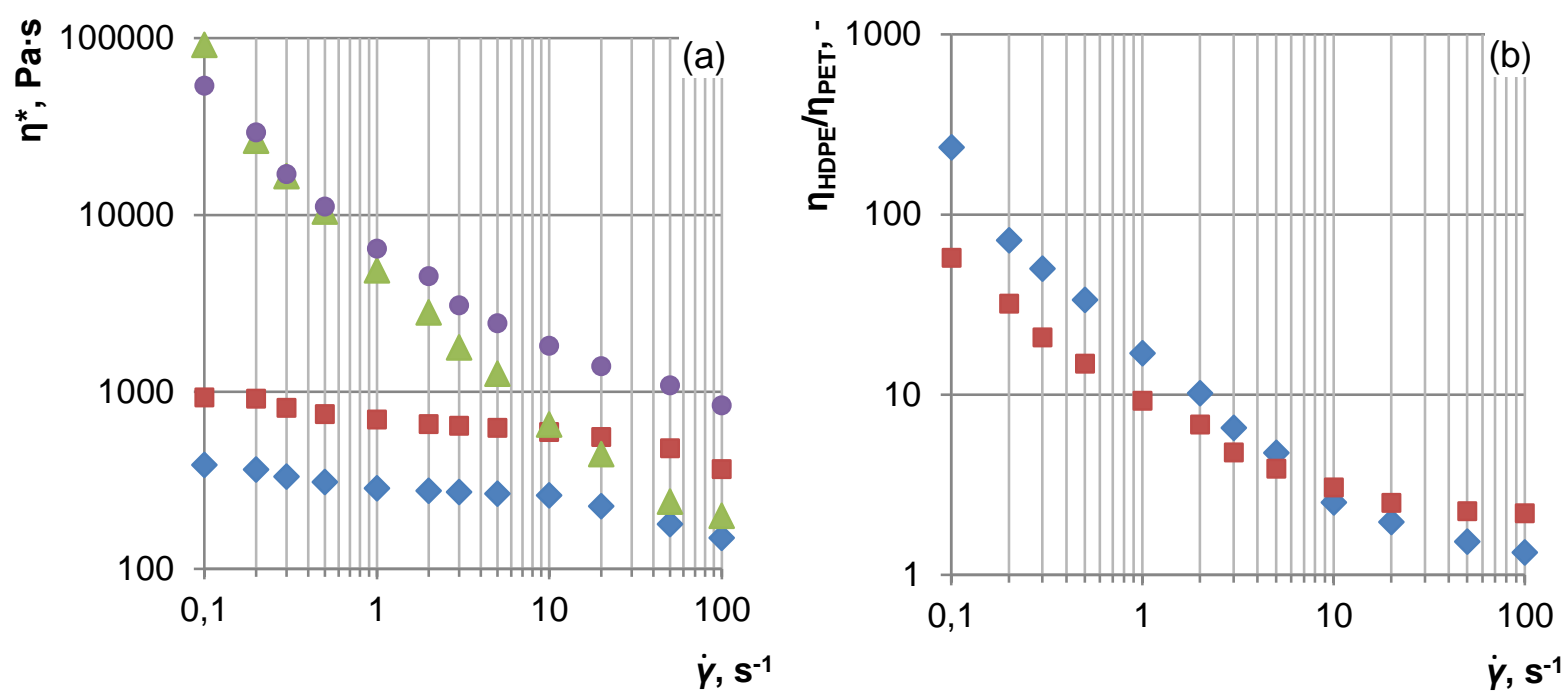

Figure 1. (a) Viscosity of ( $\bullet$ PET, ( $\bullet$ ) PET with 4\% SEBS-g-MA, ( $\triangle$ ) HDPE, (•) HDPE with 4 v\% SEBS-g-MA as a function of shear rate, at $275^{\circ} \mathrm{C}$; (b) viscosity ratio of $\mathrm{HDPE} / \mathrm{PET}$, at $275^{\circ} \mathrm{C}$, (४) without SEBS-g-MA, ( $\square$ ) HDPE/PET with 4\% SEBS-g-MA 


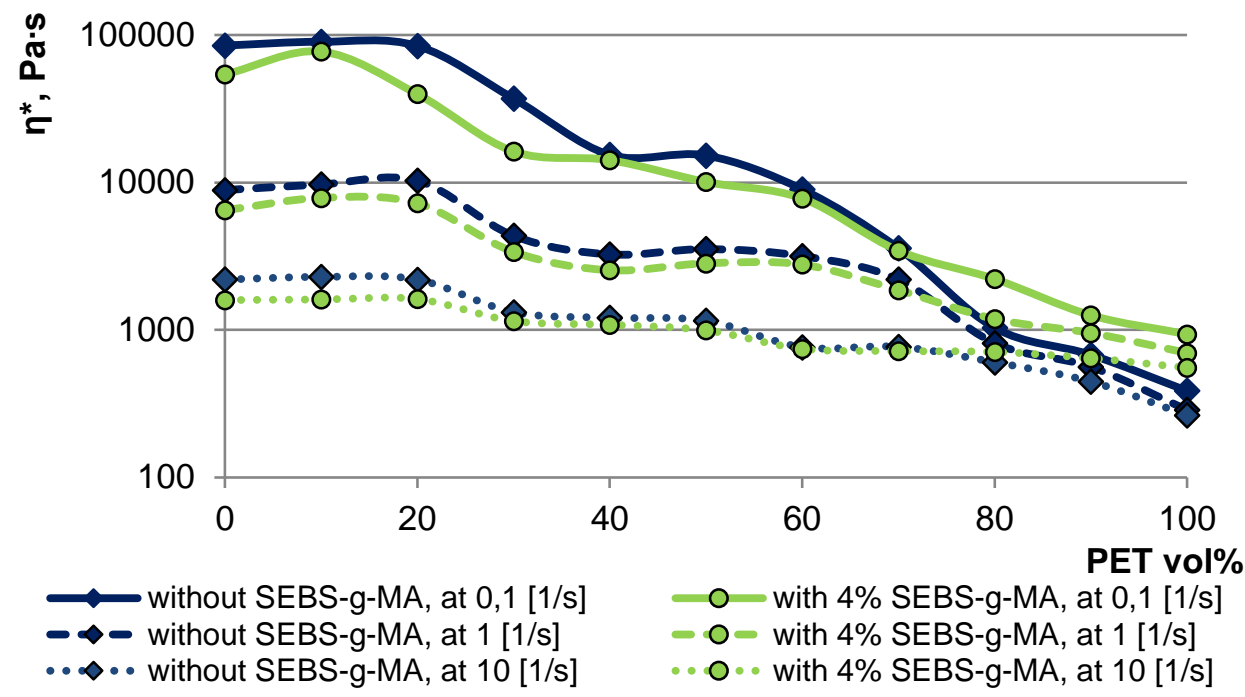

Figure 2. The complex viscosities of PET/HDPE blends, without and with 4 vol\% SEBS-g-MA as a function of shear rates (at three different values: $0.1,1.0$ and $10.01 / \mathrm{s}$ ) 

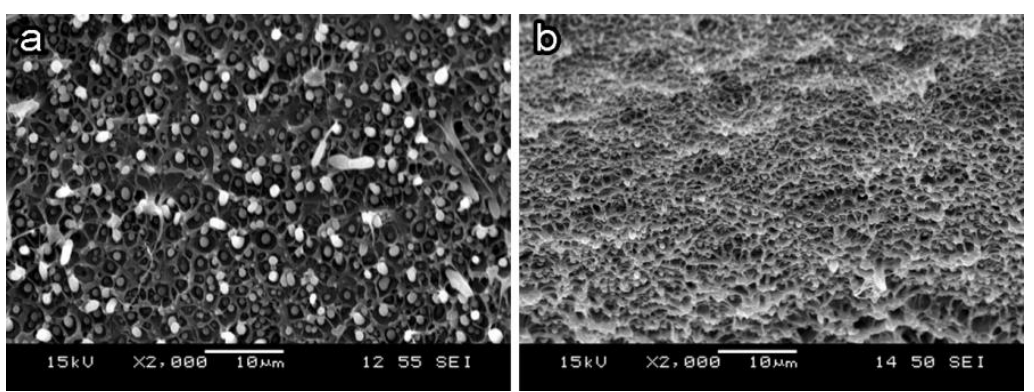

Figure 3. Fracture surface of Morphology structure of PET/HDPE blends,), fracture surface and parallell to the shear flow, after extrusion: (a) 10/90 (b) 10/90 + 4 vol\% SEBS-g-MA 

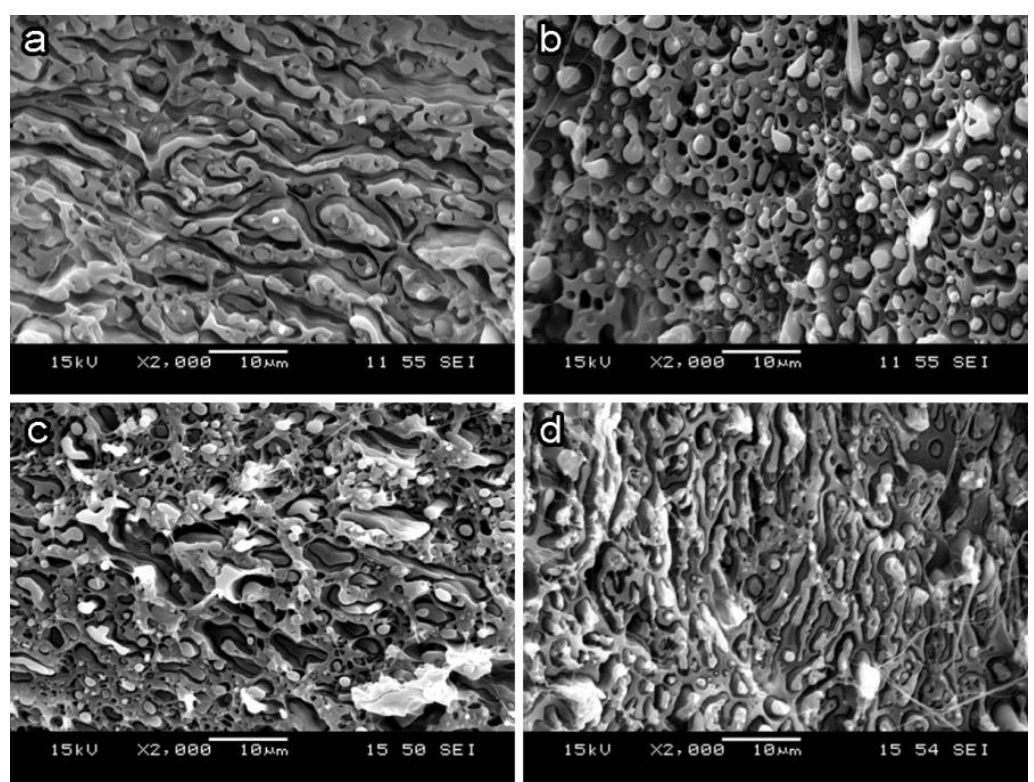

Figure 4. Fracture surface of PET/HDPE blends, (after extrusion), with a composition-ratio of: (a) 30/70; (b) 40/60; (c) 30/70 + 4 vol\% SEBS-g-MA; (d) 40/60 + 4 vol\% SEBS-g-MA 

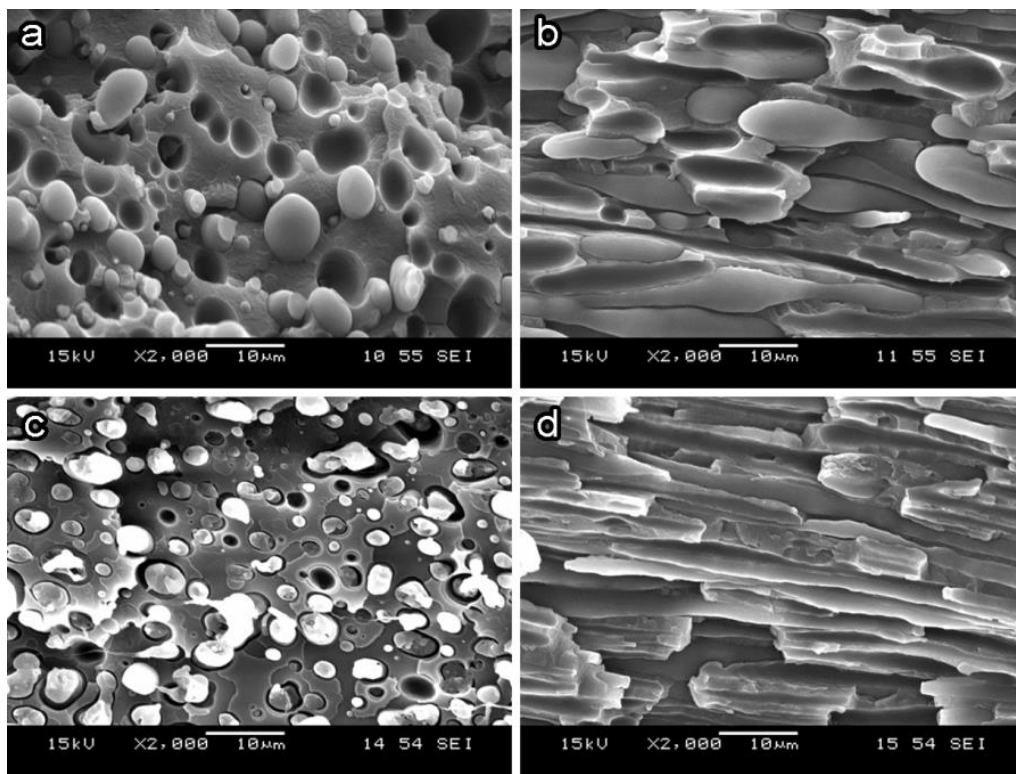

Figure 5. Morphology structure of PET/HDPE blends, fracture surface and parallelly to the shear flow, after extrusion: (a) 60/40, surface; (b) 60/40, parallel; (c) 60/40 + 4 vol\% SEBS-g-MA, surface; (d) 60/40 + 4 vol\% SEBS-g-MA, paralell 


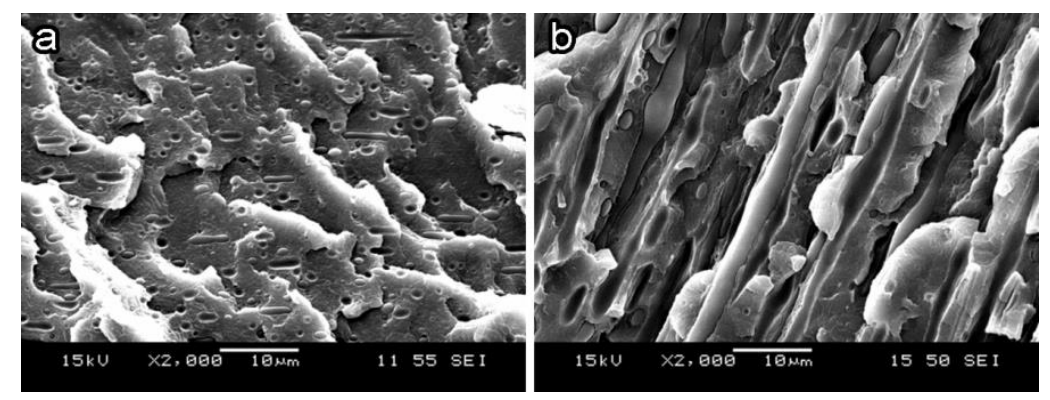

Figure 6. Morphology structure of PET/HDPE blends, fracture surface and parallelly to the shear flow, after extrusion: (a) 90/10 parallel; (b) 90/10 + 4 vol\% SEBS-g-MA, paralell 


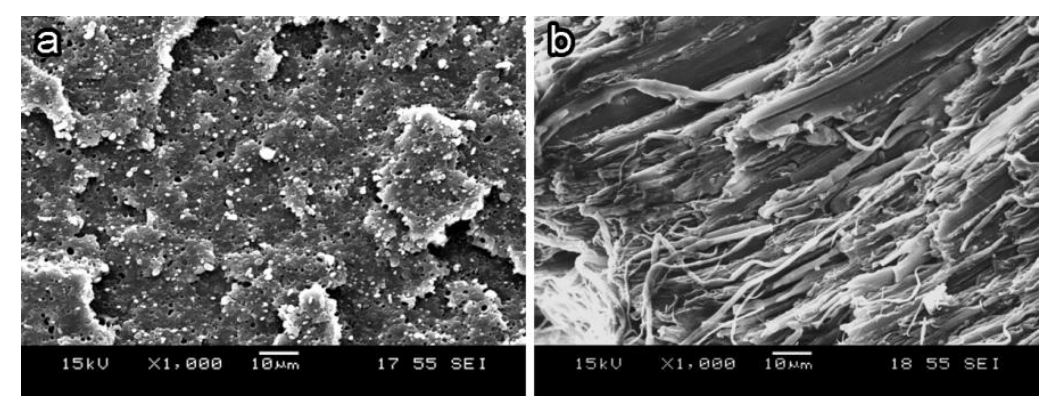

Figure 7. Morphology of 20/80 PET/HDPE blend, after injection moulding: (a) core; (b) shell 


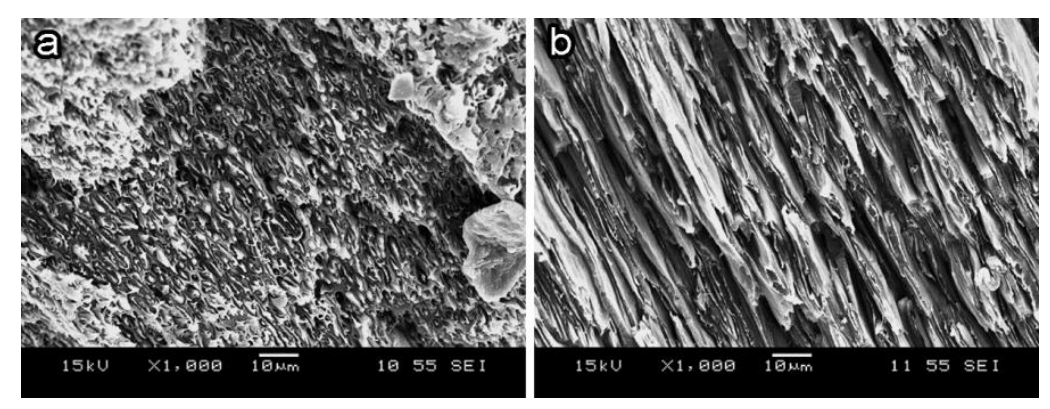

Figure 8. Morphology of 40/60 PET/HDPE blend, after injection moulding: (a) core; (b) shell 


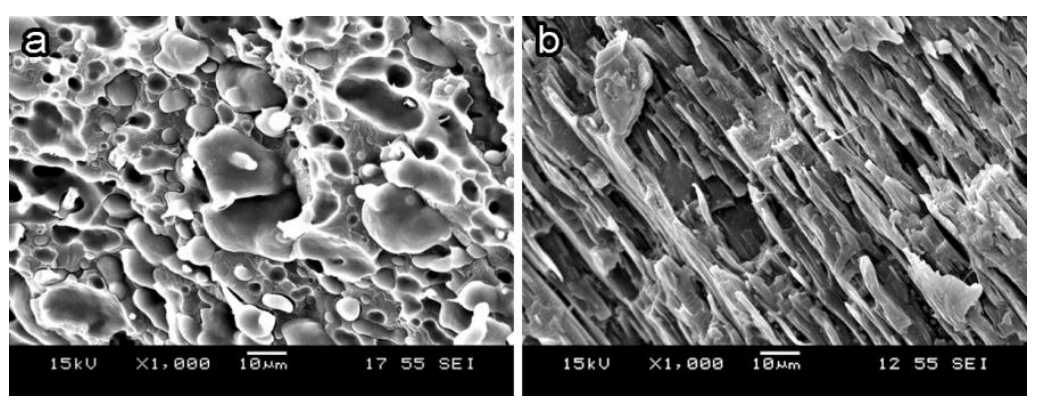

Figure 9. Morphology of 60/40 PET/HDPE blend, after injection moulding: (a) core; (b) shell 


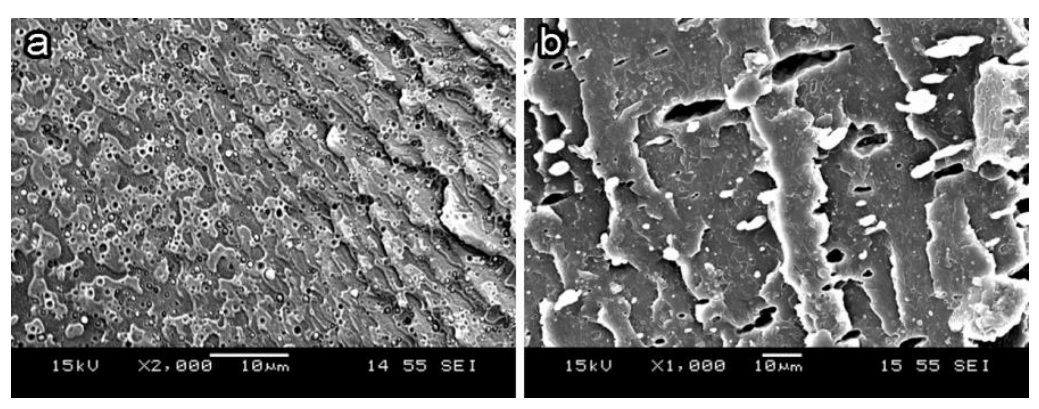

Figure 10. Morphology of the core of 90/10 PET/HDPE blend, after injection moulding: (a) without SEBS-g-MA; (b) 4 vol\% of SEBS-g-MA 


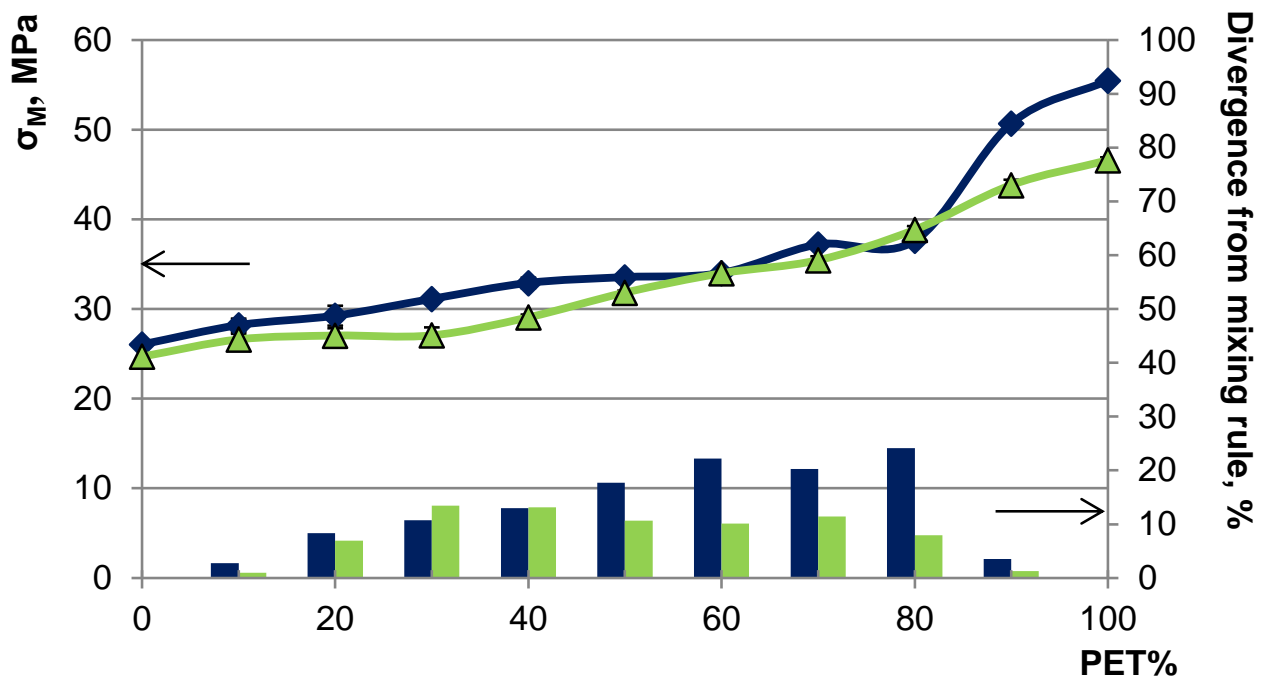

$\begin{array}{ll}\longrightarrow \text { divergence - without SEBS-g-MA } & \text { divergence - } 4 \% \text { SEBS-g-MA } \\ \sim \sigma \text { - without SEBS-g-MA } & \triangle \sigma-4 \% \text { SEBS-g-MA }\end{array}$

Figure 11. Tensile strength of PET/HDPE blends $\left(\sigma_{M}\right)$ without or contained with SEBS-g-MA as a function of PET content; and the divergence from the theoretical mixing rule 


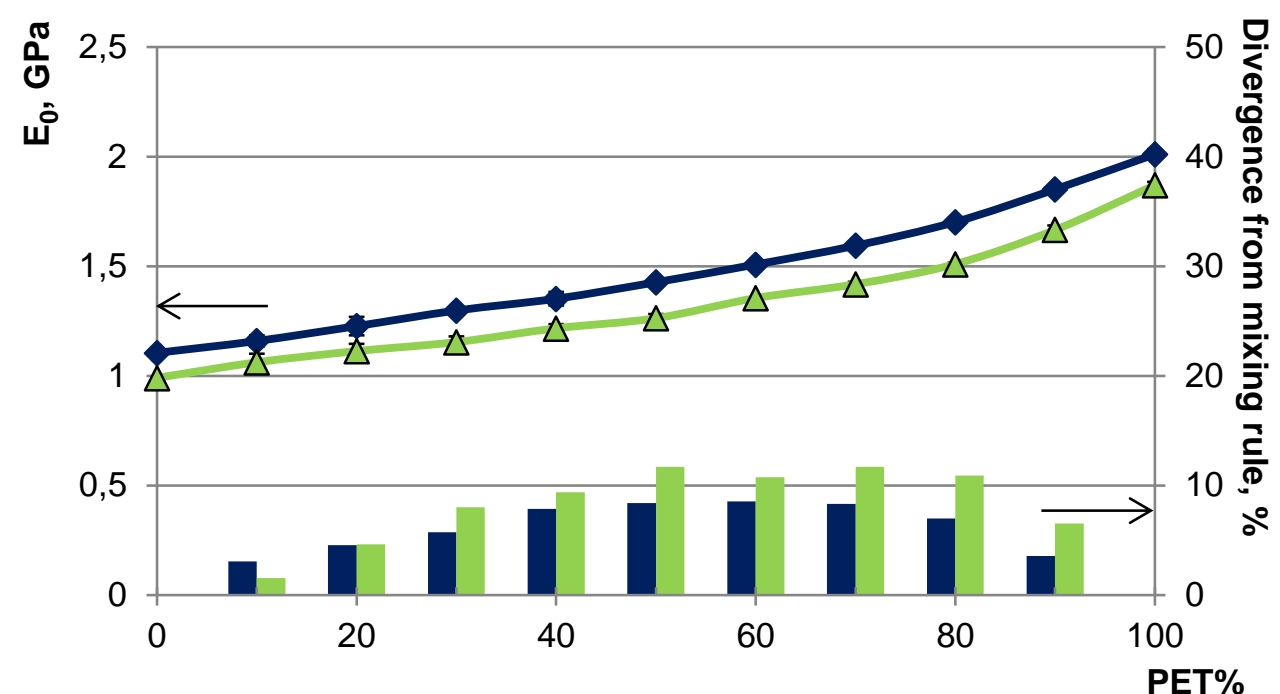

$\begin{array}{ll}\text { divergence - without SEBS-g-MA } & \text { divergence - } 4 \% \text { SEBS-g-MA } \\ \sim \text { E - without SEBS-g-MA } & \triangle E-4 \% \text { SEBS-g-MA }\end{array}$

Figure 12. Young's modulus of PET/HDPE blends $\left(E_{0}\right)$ without or contained with SEBS-g-MA as a function of PET content; and the divergence from the theoretical mixing rule 


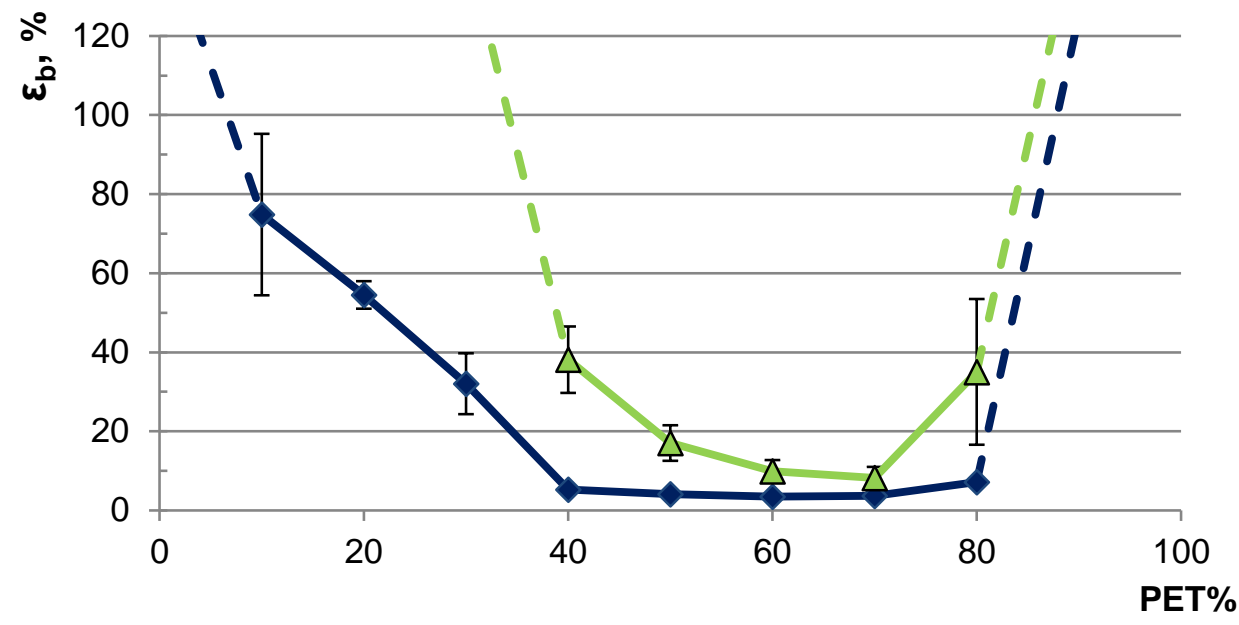

$\rightarrow$ without SEBS-g-MA $\triangle 4 \%$ SEBS-g-MA

Figure 13. Tensile elongation at break of PET/HDPE blends $\left(\varepsilon_{b}\right)$ without or contained with SEBS-gMA as a function of PET content (where dashed lines mean no break until 120\% elongation) 